\title{
State of the Art: A.I. through the (artificial) artist's eye
}

\author{
Anna Notaro \\ Duncan of Jordanstone \\ College of Art \& Design \\ University of Dundee, Dundee, UK \\ a.z.notaro@dundee.ac.uk
}

\begin{abstract}
This paper builds on the premise that art has a significant role to play in engaging with and exploring new technologies and in contributing to interdisciplinary conversations. Artists have often been pioneers in reflecting upon social and technological transformations by creating work that makes explicit the dangers, but also the exciting possibilities ushered in by innovation. After having, albeit briefly, traced the history of art engagement with technology (computer/net-art, generative art), the paper will focus on Al-art, now defined as GAl-art, to understand whether artificial intelligence is "set to become art's next medium?" The question was prompted by the sale at Christie's in October 2018 for $\$ 432,500$ of a portrait entitled Edmund de Belamy, a work created by an algorithm called Generative Adversarial Network (GAN). The source code used by the Paris based art collective Obvious (borrowed from Al researcherlartist Robbie Barrat) to create the "artwork" triggered a debate as to the authenticity, authorship and ethics of using GAN to produce Al-art. The paper will contribute to such debate by exploring also the implications of systems more sophisticated than GAN - which seem to be able to act as "autonomous artificial artists" and produce new styles of art - and by showcasing the works of some of the most representative machine vision researchers/artists - Anna Ridler and Mario Klingeman, among others. Al artworks raise major philosophical questions, the meaning to be human in a hyper-connected world and the true nature of human creativity. In fact conceptualising Al through the artificial artist's eye might even challenge our understanding of what it means to be human.
\end{abstract}

Generative art. Artificial artist. Creativity. GAN. CAN. GAl-art.

\section{INTRODUCTION}

In 2009 I wrote a paper in which I argued that the contemporary interest in the human-like artificial actor (synthespian) should have been considered in the context of humanity's fascination with the idea of artificial life created from inanimate materials. Such a fascination is evidenced by the proliferation of stories and artefacts, which express the mingled fear and desire for autonomous machines, which can either make humans entirely redundant, or, in the more optimistic scenario, provide a solution to the limitations of our imperfect bodies (Notaro 2009). As it will become evident below there is an interesting parallelism between the early $20^{\text {th }}$ century idea of dispensing with the services of human actors (Craig's marionette theatre, Artaud's puppets, Mejerhold's bio-mechanical actors) and today's speculations surrounding the "artificial artist". Comparisons have also been drawn with previous art movements, it has been suggested that with Fountain Duchamp:

Took a urinal, turned it on its side, and "created a new thought for that object," forcing us to consider if it could be art. Artificially intelligent art flips this, not just creating a new thought for an object, but creating an object capable of doing some of the thinking and creating for us (Bailey 2018).

More about the "creative potential" of the object later, in the meantime I would suggest that Duchamp's conceptualist ghost is not the only one haunting the machine, therein lie also the ghosts of surrealists like Breton, Ernst, Dalí and Bellmer, the creator of strange fetish-like morphed creatures. As we know morphing is an established artistic practice and a standard special effect in Hollywood productions and yet, I find that it has not lost any of its surreal qualities (the dream of the body assembled from different parts) in the "human-like" 
figures generated in endless loops by today's algorithmic art.

\section{G IS FOR... GENERATIVE ART}

But what exactly "generated by the algorithm" mean? Is there a consensus about what generative art (G-art) is? Does it differ from Al- art? Galanter (2019) offers some answers when he states, "what is definitive about generative art isn't what it is, but rather how it is made", before referring to his often cited definition:

\begin{abstract}
Generative art refers to any art practice where the artist uses a system, such as a set of natural language rules, a computer program, a machine, or other procedural invention, which is set into motion with some degree of autonomy contributing to or resulting in a completed work of art (Galanter 2019).
\end{abstract}

I would qualify the above as a pragmatic "working definition" for it avoids dwelling on philosophical questions of ontology (what is the essence of art and creativity in connection to/with technology) while focusing on process instead. This does not mean of course that such philosophical questions are not worth asking, which will be the case in the next section.

There is no room here to clarify the subtle distinctions among the names: "computer art", "netart", "electronic art", "computer assisted art" (C-art) - the list could be longer - I refer the reader to Boden's useful disquisition (Boden 2010). What I propose instead is the new umbrella term of "GAIart" to include current art produced by using $\mathrm{Al}$ systems, while simultaneously recognising the influential legacy of past generative art (G-art).

What is occasionally omitted when discussing the history of G-art, and has implications for GAl-art as we shall see below, is that for early practitioners like Bense, Metzger, Nake "generative art ... was tied to a generative understanding of art's political role", for them art:

Could be structured according to alternative logics - the eruptive spontaneity of the creative act $\ldots$ or the mutually beneficial, horizontal processes of communication and collaborative action (Caplan 2020).

As I type these words my eyes fall on a gorgeous picture by Cornelia Sollfrank which graces the wall of my studio, as shown in Figure 1.

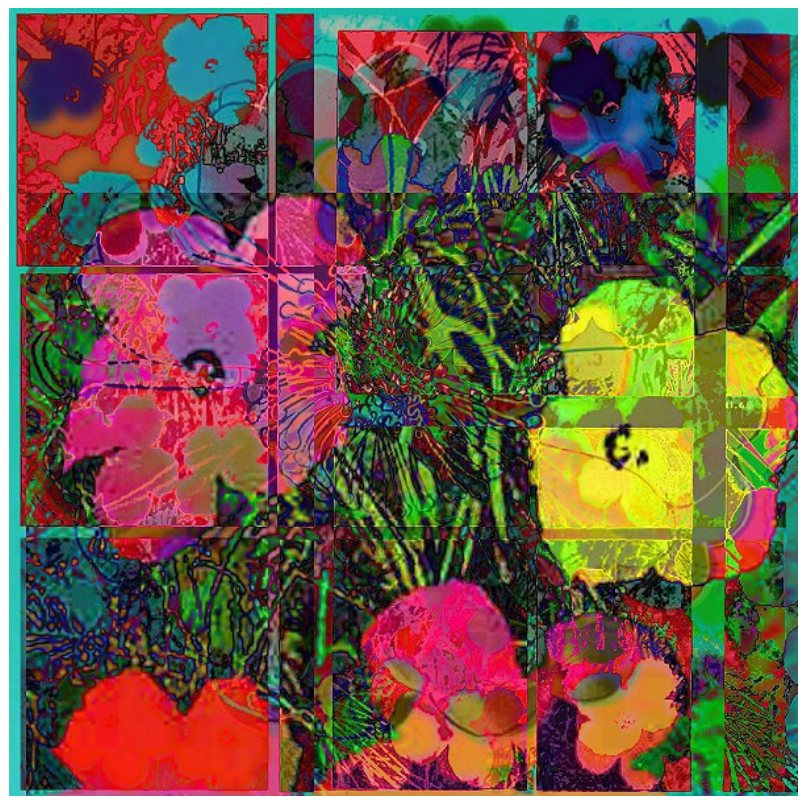

Figure 1: anonymous-

warhol_flowers@Jan_3_14.40.53_2012, Cornelia Sollfrank, 2012.

Over the past twenty-five years, the German hacker, cyberfeminist, conceptual and net.artist, Cornelia Sollfrank has been adapting subversive artistic strategies of the classical avant-gardes to digital media. Under the motto "the smart artist makes the machine do the work" Sollfrank (2004) conceived - in collaboration with several coders the "net.art generator", a programme that automatically creates digital collages from pictures available on the Internet. (https://nag.iap.de/). Sollfrank's generative art has a social conscience, to quote the title of Caplan (2020); hence it is in line with the early G-art practitioners mentioned above. Specifically, the picture on my wall is from a series of net-generated artworks produced using the iconic Warhol Flowers in order to investigate the paradoxes of intellectual property and question, through automation, concepts like authorship, creativity and (male) artistic individual genius (Sollfrank 2012). Interestingly, similar concerns are shared by some contemporary GAl-art practitioners as well.

\section{$2.1 \mathrm{C}$ is for... creativity}

As stated above questions of ontology, regarding what constitutes the essence of human art and creativity in connection with technology are challenging, but still worth asking. The main challenge lies in the fact that we struggle to define human creativity, let alone to understand what happens when artists and machines interact to create "something" new, is that "something" art? Is it co-creation? What is sure is that we seem to be obsessed with the idea of creativity, especially with its economic value for the business world. This is because the traditional, Romantic idea of creativity 
as a state of being (rather than doing) has been replaced by a new type of creativity whose main merit lies in "making" a product that can be "measured", tested and ranked (the notion of happiness has undergone a similar fate). I would argue that GAl-art has revived interest in such questions by stimulating new intellectual energy from critics, academics and artists and by injecting a sense of urgency, given the speedy pace of technological innovation in the Al sector. The newly opened University of the Arts London Creative Computer Institute, exhibitions like "Al: More than Human" (Barbican, London 16 May-26 August 2019) and companies such as the Google-owned DeepMind, The Google Brain project Magenta or the international art collectives TeamLab, to name a few, are evidence of the huge intellectual and financial interest in the sector.

But let's revisit, albeit briefly, some previous contributions to the ontological questions raised above. Already in 1973, eighteen years after John McCarthy coined "artificial intelligence", the question of whether "Al will eventually replace the artist", was posed by artist and professor of computational art Ernest Edmonds. His answer was "no", an opinion confirmed recently when he stated:

\begin{abstract}
Art is a human activity for human purpose, for human consumption, consideration, and enrichment. And the making of the art is as much a human process as the consumption of it. And so, I would say that if machines could make art for machines, that would be fine. But it would not necessarily have any relevance whatsoever to human beings (Cizek, Uricchio \& Wolozin 2019).
\end{abstract}

Others like Harold Cohen, a pioneer of algorithmic art but "first and foremost a painter" (Garcia 2016) have, in time, considered the computer programme more as a partner. Cohen's drawing and colouring programme AARON, developed over forty years and exhibited all over the world, is a case in point. Cohen compared his relationship with AARON to that of Renaissance artists and their studio assistants, and as to whether the work produced was evidence of intelligence, Cohen argued that: "AARON did just what human artists did, taking knowledge of forms and applying them to the creation process" (Garcia 2016).

Reflecting upon human-machine interaction Boden (2010) has identified three types of human creativity, it is combinational, it involves exploration and it is transformational. In my view the inherent dynamism of such definitions seems very much in tune with that emphasis on newness and production that our contemporary idea of creativity values so highly, and a good fit for GAl-art.
Having considered Boden's creativity theory Galanter (2019) astutely suggests that for a generative art system to be creative it needs to be an "adaptive system", that is able to "modify their structure or behaviour to maintain their integrity in response to changes in the environment". This is akin to what machine learning entails, that is the capacity of the algorithm to change and "adapt" due to its interaction with data. But can we "test" whether what the Al system produces is art or not? If "art is for human consumption", as Edmonds put it, then one should ask some humans by using a Turing test for art. This is exactly what Ahmed Elgammal, director of the Art and Artificial Intelligence Lab at Rutgers University did:

\begin{abstract}
We mixed human-generated art and art from machines, and posed questions - direct ones, such as "Do you think this painting was produced by a machine or a human artist?" and also indirect ones such as, "How inspiring do you find this work?" We measured the difference in responses towards the human art and the machine art, and found that there is very little difference. Actually, some people are more inspired by the art that is done by machine (Christie's 2018).
\end{abstract}

Whether the poll is evidence enough that the algorithm produces art is, of course, an open question.

One of the latest contributions to the machinecreativity debate is by mathematician Marcus Du Sautoy (2019), who proposes the Lovelace Test. To pass it: "an algorithm must originate a creative work of art such that the process is repeatable .... and yet the programmer is unable to explain how the algorithm produced its output". Du Sautoy concludes by suggesting that although "Al is a long way from matching human creativity, it has its part to play in making us more creative", the machine is "a tool for extending human creativity" at least until "it has become conscious", which Du Sautoy assumes it will.

Interactive artist Rama Allen (2018) also thinks that Al can make us more creative and thus create a new kind of art:

We as artists can now truly collaborate with a tool to harness new abilities, tap into greater complexities, explore possibilities, and thus create a new kind of art. The output of this expression differs categorically from all art previously made by humans through history, and this intelligent contribution inspires deeper investigations of the meanings of authorship, creativity, and art. I propose we call this new artistic language "augmented art".

What emerges is a notion of "augmented creativity", which further enhances that of human creativity as defined by Boden (2010). 
Augmentation alone might not settle all the philosophical issues mentioned above but perhaps it represents an adequate characterisation of the current state-of-the-art. One even endorsed by the "new master of $\mathrm{Al}$ created painting" Mario Klingemann, who went on to suggest that "what Al really adds is new ideas - it's about augmenting the human imagination" (Carstensen 2018, emphasis mine).

\subsection{He is a jolly Goodfellow}

Algorithmically derived art is not a new genre, "Roman Verostko and the Algorists were an early1960s group of visual artists that designed algorithms that generated art" (Cizek, Uricchio \& Wolozin 2019), however for a new wave of Algorists to appear one needs to wait till computer scientist Ian Goodfellow released his influential paper outlining the concept of generative adversarial networks (GANs) in 2014. He developed a system of two neural networks: a discriminator and a generator. The generator looks at large sets of training data and tries to produce something that resembles the data so closely that the discriminator cannot tell it was produced by another network. The goal, Bailey (2020) notes, is "to optimize the system so that the generated output is impossible to distinguish from the real inputs". The availability of the system, together with an explosion in publicly available data has certainly democratised Al based creative practice, while also making possible more controversial applications, like the production of "deepfake" videos, an unfortunate corollary to our "post-truth" age.

GANs came to the attention of the general public in October 2018 when, despite an estimated sale price of between $\$ 7,000$ to $\$ 10,000$, a portrait entitled Edmund de Belamy, from La Famille de Belamy, sold at Christie's in New York for $\$ 432.500$. The name "Belamy" was a reference to the creator name of GANs, Ian Goodfellow, that roughly translate to "Bel ami" in French. "Authors" of the portrait were Obvious, "a Paris based collective of artists, Machine Learning researchers and friends interested in Al for Art" (Obvious 2018). The sale raised a few eyebrows amongst art critics and Al artists alike. First of all the quality of the image was poor, of rather low resolution, secondly it had been produced by an algorithm the artists did not write, (it was an Old Masters GAN created by Robbie Barrett in 2014, although Obvious asked for "tweaks"), lastly it was packaged in a gilt frame with a segment of the algorithm's code for a signature and no acknowledgment of Barrett's contribution. Also, the publicity material circulated prior to the sale quoted the artists' motto, "creativity isn't just for humans", it was precisely this motto which stirred up the media hype surrounding the Al portrait and demonstrated Obvious' "willingness to embrace a particular narrative about $\mathrm{Al}$ art, one in which they credit the algorithm for creating their work" (Vincent 2018). As Vincent (2018) explains, "For Al researchers and artists, this is misleading. It gives readers the false impression that machine learning systems are more complex and autonomous than they actually are". It has to be noted that Obvious themselves have implicitly acknowledged the stunt character of their motto when they admitted: "We found that portraits provided the best way to illustrate our point, which is that algorithms are able to emulate creativity" (Christie's 2018, emphasis mine).

Misleading statements and attention-seeking attitudes are nothing new in the art world, for Bogost (2019) Al painting seems to be "the machine-learning equivalent of a urinal on a plinth". As for key questions about art and creativity which works like Belamy open up, Richard Lloyd, the International Head of the Prints and Multiples department at Christie's explains:

\begin{abstract}
Everybody has their own definition of a work of art. I've tended to think human authorship was quite important - that link with someone on the other side. But you could also say art is in the eye of the beholder. If people find it emotionally charged and inspiring, then it is. If it waddles and quacks, it's a duck (Nugent 2018).
\end{abstract}

The problem with Belamy is that the portrait is not "emotionally charged and inspiring", its sole interest lies in the way in which it was made - other Al works are more aesthetically expressive and/or evocative, as we shall see below. Perhaps instead of resorting to the "duck test" and abductive reasoning Lloyd might have recalled Andy Warhol's famous statement, "art is what you can get away with". Warhol made business his art and this is exactly the direction that some Al artists and auction houses like Christie's are taking, to the point that one commentator has compared the current interest in Al-art to a gold rush (Bogost 2019). So it comes as no surprise that since 2018 Christie's has been staging an Art+Tech Summit on the profound implications of blockchain for artists and collectors - in recognition of an emerging crypto art market (see cryptokitties.co, crypko.ai, among others).

Interestingly, the 2019 Summit's accompanying exhibition included a moving-image artwork Yugen, by filmmaker and artist Martha Fiennes. Contrary to Belamy, Yugen appears to be a much more compelling piece. Asked how technology and creativity can work together Hayek's reply reflects some ambiguity: "To me, technology is only as powerful as the human consciously using it, or alternatively, perhaps unconsciously being used by it", before concluding "We're handing over potential to the computer to throw up these synchronicities, 
so perhaps there is an intelligence somewhere. Every time you see the work, it is fresh, and alive, suggesting that there is creativity in the technology" (Christie's 2019).

\subsection{From GAN to CAN}

The question of agency - whether the human is consciously using the technology or is unconsciously being used by it - is particularly important for artist Sougwen Chung. For her:

\begin{abstract}
Models of co-creation foreground parity and balance ... It necessitates questions around control and human agency, which we've lost. ... Agency as a concept is a precondition for justice. They're inextricably intertwined.
\end{abstract}

Chung's work has a "social conscience", and this is particularly evident in projects like Omnia per Omnia (2018) where she draws and performs alongside a multi-robotic system responding to livestream data from surveillance feeds in cities. Chung's works highlights the alarming lack of human consent in the way in which data is obtained to train Al technology and the risk of perpetuating cultural bias. In fact if a GAN system is trained exclusively on images of Old Western Masters, the new images produced will reflect a culturally skewed perspective. Chung's work is also interesting in that, in order to avoid some of the above risks, she trains GANs on her own drawings and paintings.

Similarly, Helena Sarin combines analogue and physical art-making methodologies with Al techniques. The result is that "Sarin has developed her own language that is warmer and more physically engaging than push-button GAN image" (Bailey 2020). Social and cultural concerns also inspire the work of Anna Ridler; Mosaic Virus (2019) is a project that draws parallels between tulip mania in 17th century Europe and current speculation surrounding cryptocurrencies. As Ridler explains: "I wanted to draw together ideas around capitalism, value, and the tangible and intangible nature of speculation, and collapse from two very different yet surprisingly similar moments in history" (Boddington 2019).

In the Introduction I noted how the ghost of Surrealism was haunting the machine, Mario Klingemann's work is a case in point. The hallmark of Klingemann's aesthetic, explicit in works like Memories of Passersby I (2018) is described as "haunted" (Bailey 2020) and the artist himself finds parallelisms between the surrealist Max Ernst and his own machine learning-based artistic practice. As he put it:

The machine doesn't know how the world works and juxtaposes elements that do not belong together, which is what surrealism does, too... As our brains try to make sense of what we're seeing, we enter this uncanny dreamlike state (Carstensen 2018).

All the artists mentioned in this section are keen to retain, albeit under different guises, some degree of creative agency in their GAN-based production, AICAN's approach is different. AICAN, created by Ahmed Elgammal, director of the Art and Artificial Intelligence Lab at Rutgers University uses an algorithm called CAN, "creative adversarial network". AICAN is unabashedly described as "a new system for generating art", one that:

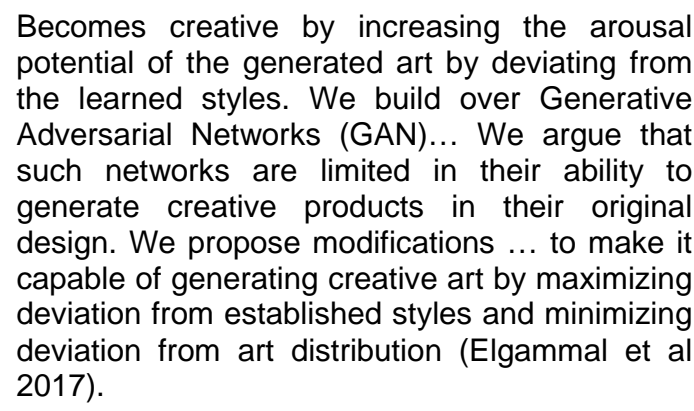

Bogost (2019) discusses the works produced by AICAN and exhibited in New York City in March 2019. The show is presented as a collaboration between an "autonomous Al artist" (AICAN) and its creator Ahmed Elgammal, and as "the first solo gallery exhibit devoted to an Al artist" (although AICAN's work has been exhibited around the world since 2017). I would argue that, just like in the case of Christie's Belamy auction discussed above, marketing reasons underpin the narrative of the "autonomous Al artist". Bogost (2019) astutely observes that "Elgammal's financial interest in AICAN might explain his insistence on foregrounding its role". As the web site of Elgammal's spin off company Artrendex, states:

\begin{abstract}
The key feature of our innovation is the ability to quantify aesthetic concepts that for long-time were believed to be subjective. Based mainly on visual analytics, our models were shown to be able to predict style changes and trends in historical data. In an art market that is worth more that 64 billion dollars, where the mass of that market is art bought as investment, comes the need for data-analytics tools that assert the potential value of art (http://www.artrendex.com/).
\end{abstract}

AICAN's "art" is above all a commodity, one that perfectly encapsulates an idea of creativity as measurable and quantifiable. Gone are (flawed), subjective aesthetic concepts, AICAN holds the perfect technological "solution" to art, only how ironic if human flaws were to be replaced by a culturally biased algorithm trained on 80,000 images taken exclusively from the Western art canon! 


\subsection{Abraham the autonomous artificial artist}

In a piece aptly entitled "Artist in the Cloud" artist/programmer Gene Kogan (2019a) introduced to the world Abraham, the first autonomous artificial artist (AAA). Abraham is "an open project to make an autonomous artificial artist, a crowd-sourced Al that generates art". Adopting a somewhat messianic tone - Abraham was a prophet after all and Kogan his contemporary reincarnation - the AAA is described as "a sovereign creative spirit who generates original art". Its main criteria are: autonomy (it has its own agency), originality (it has its own creativity) and uniqueness (its artworks may be copied but its creativity can't be replicated elsewhere) (Kogan 2019a). The new generative art program complies with specific technical constraints and a sophisticated system of governance. In brief:

\begin{abstract}
The program is learned from the collective input of a decentralized group of actors who crowdsource data, code, curation, and governance to the AAA. In order to coordinate them, a decentralized autonomous organization (DAO) is formed which is open to anyone. Decentralization prevents any one party from exerting too much influence on the AAA, as that would compromise its originality and autonomy (Kogan 2019a).
\end{abstract}

What Kogan has in mind is a generative art programme emerging from the collective intelligence, one where the profits (for works produced and sold on the market) are shared (via digital currency) among the people who build and feed it. Ironically, he notes:

Despite the talk of automation... Abraham is an essentially humanist endeavour. Whereas the popular conception of $\mathrm{Al}$ is one of some alien entity separate from people and here to replace us, an AAA is the precise opposite. It is made from human intelligence, a vehicle to blend our collective wisdom into something transcendent (Kogan 2019b).

Kogan declares that he is "no utopian" (Kogan 2019a), and yet it is hard not to detect more than a hint of utopianism when he states that one goal is "to make something beautiful: a blender for the collected creativity of the world" (Kogan 2019b).

Abraham is an amazingly ingenious and fascinating project, one that combines echoes of that "mutually beneficial, horizontal processes of communication and collaborative action" typical of early G-art (see section 2. above), together with ideas of the "hive mind" and "collective intelligence" from the optimistic early days of the Internet. However, the predominant characteristic is a kind of messianic techno-spiritualism deeply rooted in established religious tropes. Abraham's home page (https://abraham.ai/) refers to "Covenant",
"Miracles", "Gospel" and its beta version is called "Genesis". For all its emphasis on the benefits of collectivism and distributed agency, one might have expected a different narrative for AAA, instead the latest artificial artist turned out to be called Abraham like the patriarch known for obeying unquestionably the commands of one God.

\section{CONCLUSION}

Contrary to Kogan I have no prophetic inclinations, hence this section won't be discussing the future of GAl-art or take sides on whether or not the machine will, in time, reach a degree of consciousness to rival our human capacity to produce art and tell stories. I would recommend instead that we direct our intellectual energies towards investigating the emerging applications of $\mathrm{Al}$ as a tool for the organisation and categorisation of art, to detect forgery and influence the art market. Furthermore, it is critical that the conversation regarding the legal implications, ethics, and future of $\mathrm{Al}$ in the art world (and not just) are interdisciplinary. The question of agency in relation to the use of $\mathrm{Al}$ technologies will continue to be paramount, we need to remain alert to the fact that Al offers no neutral technological solution and that such systems are not unclouded by bias.

According to philosopher Luciano Floridi (2018) the arts we produce as humans are part of what he calls our "semantic capital", which includes also ideas, insights, discoveries, inventions, traditions, cultures, languages, religions, sciences, narratives, stories, poems, customs and norms, music and songs, games and personal experiences. Crucially, Floridi points out, such semantic capital:

Is no longer just analog, it is also increasingly digital, and may not be generated solely by human agents... How the shift from an analog to an increasingly digital semantic capital is going to affect our semanticisation of our own identities, our lives and our realities is still to be understood.

I suggest that GAl-art by calling attention to the relationship between humans and the computers (non-human agents) that surround us and the powerful impact that technology has on our relationships with each other has the potential to help us understand the true value of our evolving (digital) semantic capital.

\section{REFERENCES}

Allen, R. (2020) Al Will Be the Art Movement of the $21^{\text {st }}$ Century, Quartz. https://qz.com/1023493/aiwill-be-the-art-movement-of-the-21st-centuryl (retrieved 1 March 2020). 
Bailey, J. (2018) Al Just Got Awesome, Artnome. https://www.artnome.com/news/2018/3/29/ai-artjust-got-awesome (retrieved 3 March 2020).

Bailey, J. (2020) The Tools Of Generative Art, Art in America. https://www.artnews.com/art-inamerica/features/generative-art-tools-flashprocessing-neural-networks1202674657/?fbclid=IwAR3ZySihwq2dAw 8NiysCOEnlyWf10-

gJnfmoiolLG9oigq0JmIXGasEfg (retrieved 2 March 2020).

Boddington, R. (2019) Anna Ridler uses Al to turn 10,000 tulips into a video controlled by bitcoin. https://www.itsnicethat.com/articles/anna-ridlerdigital-art-280619\#.XRsI2CWsL4Y.twitter (retrieved 15 March 2020).

Boden, M. A. (2010) Creativity and Art: Three Roads to Surprise. OUP, Oxford.

Bogost, I. (2019) The Al-Art Gold Rush is Here. https://www.theatlantic.com/technology/archive/201 9/03/ai-created-art-invades-chelsea-galleryscene/584134/ (retrieved 3 March 2020).

Caplan, L. (2020) The Social Conscience of Generative Art, ArtNews.

https://www.artnews.com/art-inamerica/features/max-bense-qustav-metzgergenerative-art-1202674265 (retrieved 7 March 2020).

Carstensen, J. (2018) all turtles, The New Master of Al created 'Painting'. https://www.allturtles.com/2018/11/16/the-new-master-of-aicreated-painting/ (retrieved 4 March 2020).

Christie's (2018) Is artificial intelligence set to become art's next medium? https://www.christies.com/features/A-collaborationbetween-two-artists-one-human-one-a-machine9332-1.aspx (retrieved 11 March 2020).

Christie's (2019) A conversation between spirituality and technology. https://www.christies.com/features/Martha-Fiennesand-Salma-Hayek-on-Yugen-9431-3.aspx (retried 1 March 2020).

Cizek, K. Uricchio, W. and Wolozin, S. (2019) Part 6: Media Co-Creation with Non Human Systems. https://wip.mitpress.mit.edu/pub/collective-wisdompart-6 (retrieved 10 March 2020).

Du Sautoy, M. (2019) The Creativity Code. $4^{\text {th }}$ Estate, London.

Elgammal A., Lui, B., Elhoseiny, M. and Mazzone, M. (2017) CAN: Creative Adversarial Networks, Generating "Art" by Learning About Styles and Deviating from Style Norms. https://arxiv.org/abs/1706.07068 (retrieved 15 March 2020).
Floridi, L. (2018) Semantic Capital: Its Nature, Value, and Curation. Philos. Technol. 31, 481-497 https://doi.org/10.1007/s13347-018-0335-1 (retrieved 16 March 2020).

Galanter, P. (2019) Artificial Intelligence and Problems in Generative Art Theory. Electronic Visualisation and the Arts (EVA 2019), London, UK, 8-11 July 2019.

http://dx.doi.org/10.14236/ewic/EVA2019.22 (retrieved 5 March 2020).

Garcia, C. (2016) Harold Cohen and AARON - a 40 year collaboration. https://computerhistory.org/blog/harold-cohen-andaaron-a-40-year-collaboration/?key=harold-cohenand-aaron-a-40-year-collaboration (retrieved 11 March 2020).

Kogan, G. (2019a) Artist in the Cloud. https://medium.com/@genekogan/artist-in-thecloud-8384824a75c7 (retrieved 16 March 2020).

Kogan, G. (2019b) The Spirit of Decentralization. https://medium.com/@genekogan/the-spirit-of$\begin{array}{lll}\text { decentralization-25b1ce41d4b5 } & \text { (retrieved } 16\end{array}$ March 2020).

Notaro A. (2009) Reality is in the performance: intersecting cinema, technology and the body. Refractory: a Journal of Entertainment Media, 15 http://blogs.arts.unimelb.edu.au/refractory/category/ browse-past-volumes/volume-15/ $\quad$ (retrieved 8 March 2020).

Nugent, C. (2018) The Painter Behind These Artworks Is an Al Program. Do They Still Count as Art? Time. https://time.com/5357221/obviousartificial-intelligence-art/ (retrieved 2 March 2020).

Obvious (2018) Obvious Explained, Medium. https://medium.com/@hello.obvious/ai-the-rise-ofa-new-art-movement-f6efe0a51f2e (retrieved 3 March 2020).

Sollfrank, C. (2004) net.art Generator. Verlag für moderne Kunst, Nürnberg.

Sollfrank, C. (2012) Performing the Paradoxes of Intellectual Property - A practice-led Investigation into the Increasingly Conflicting Relationship between Copyright and Art. PhD Thesis. University of Dundee 2012.

Vincent, J. (2018) How Three French Students Used Borrowed Code To Put The First Al Portrait In Christie's, The Verge. https://www.theverge.com/2018/10/23/18013190/ai -art-portrait-auction-christies-belamy-obviousrobbie-barrat-gans (retrieved 2 March 2020). 